\title{
Adsorption of heavy metals by exhausted coffee grounds as a potential treatment method for waste waters
}

\author{
H. Djati Utomo* and K. A. Hunter \\ Chemistry Department, University of Otago, P.O. Box 56, Dunedin, New Zealand \\ (Received 4 April 2006; Accepted 12 May 2006; Published 19 May 2006)
}

\begin{abstract}
The adsorption of the heavy metal ions $\mathrm{Cu}^{2+}, \mathrm{Zn}^{2+}, \mathrm{Cd}^{2+}$ and $\mathrm{Pb}^{2+}$ from aqueous solution by used coffee grounds has been investigated as a potential low-cost treatment method for heavy metal-containing waste waters that is based on a readily available natural by-product. The results show that metal ion adsorption is efficient over a fairly wide $\mathrm{pH}$ range and adsorbed metals are reversibly leached from the exhausted coffee by dilute acid without significant loss of the adsorptive capacity for subsequent re-use. [DOI: 10.1380/ejssnt.2006.504]
\end{abstract}

Keywords: coffee; adsorption; heavy metals; waste water treatment

\section{INTRODUCTION}

The re-use of natural waste materials that arise through various industrial processes for additional purposes, rather than simple disposal, makes both environmental and commercial sense [1]. Thus there has been a recent focus on agricultural and food industry wastes such as tea, coffee grounds and rice hull [2] as alternatives to synthetic ion-exchange resins or activated carbon for treating metal-containing waste streams. Tannincontaining materials such as exhausted coffee contain metal-binding polyhydroxy polyphenol functional groups [1] and are available in large quantities from the manufacture of instant coffee [3]. While there have been several studies of metal ion adsorption by tea and coffee $[4,5]$ the detailed chemistry causing their affinity for different metal ions is not yet well-known.

Here we report the use of exhausted coffee grounds as an adsorbent for the heavy metal ions $\mathrm{Cu}^{2+}, \mathrm{Zn}^{2+}, \mathrm{Cd}^{2+}$ and $\mathrm{Pb}^{2+}$ from aqueous solution. We present results describing adsorption isotherms for the metal ions, and the effects of adsorbent concentration, $\mathrm{pH}$ and metal ion concentration. In addition, we present results for the use of the adsorbent in a flow-through column.

\section{METHODS}

Commercial ground coffee (Blue Mountain variety) was sieved through an ASTM 18 stainless steel sieve $(1 \mathrm{~mm}$ mesh size). It was then repeatedly leached with excess $0.01 \mathrm{M} \mathrm{NaOH}$ solution (30 g coffee in $800 \mathrm{~mL}$ solution) at $\sim 60^{\circ} \mathrm{C}$ for $10-30 \mathrm{~min}$ with decanting and replacement of the $\mathrm{NaOH}$ until the yellow colour of the solution was no longer observed (4-6 solution changes). After this the coffee grounds were suspended in $0.01 \mathrm{M} \mathrm{HNO}_{3}$ and poured through a filter funnel containing a Whatman 114 filter and then washed repeatedly with deionized water (Millipore Milli-Q system) until a $\mathrm{pH}$ close to 6.0 was achieved. Finally the grounds were oven dried at $100^{\circ} \mathrm{C}$ for $2 \mathrm{~h}$, cooled to room temperature and sealed with parafilm. Earlier experiments [6] employed coffee leached with deionized water only, and our subsequent

*Corresponding author: han@alkali.otago.ac.nz work showed that this adsorbent continued to release soluble coffee material on subsequent exposure to aqueous solution. This complicates adsorption by competing for the metal cations. However, the alkali-leached material released very little coloured material.

Batch experiments measuring adsorption of $\mathrm{Cu}^{2+}$, $\mathrm{Zn}^{2+}, \mathrm{Cd}^{2+}$ and $\mathrm{Pb}^{2+}$ were conducted by adding known concentrations of each metal ion to a suspension of coffee adsorbent in water and equilibrating overnight at room temperature with occasional shaking. Typical conditions were $3 \mathrm{~g} \cdot \mathrm{L}^{-1}$ of coffee grounds and $200 \mu \mathrm{M}$ of metal ion. The $\mathrm{pH}$ of the suspension was then adjusted to the required value by addition of dilute $\mathrm{NaOH}$ or $\mathrm{HNO}_{3}$ as required. pH buffers were avoided since these could compete as ligands for the metal cations. After equilibration, the suspensions were filtered through a Whatman 114 filter, the filtrate was analyzed for metal ions by atomic absorption spectrometry and the amount adsorbed calculated by difference. The effects of $\mathrm{pH}$ and the concentrations of adsorbent and metal ion were studied.

Column adsorption experiments were also conducted in which solutions of metal ion concentration were pumped through a column containing $0.5 \mathrm{~g}$ of exhausted coffee adsorbent using a peristaltic pump, with aliquots of the effluent collected for metal ion analysis. The efficiency of recycling was investigated by repeated leaching of metal ions from the column using $0.1 \mathrm{M} \mathrm{HCl}$ and then readsorption of the same metal ions.

\section{RESULTS AND DISCUSSION}

All of the metal ions exhibited a strong affinity for exhausted coffee grounds as an adsorbent. Figure 1 shows how the percentage of metal ion adsorbed at $\mathrm{pH} \sim 5$ increases with the concentration of coffee adsorbent, reaching a plateau (75-90\% adsorbed) at $\sim 20 \mathrm{~g}$ coffee $\mathrm{L}^{-1}$.

The adsorption equilibria were investigated using $\mathrm{pH}$ 5.0 solutions containing $3.0 \mathrm{~g} \cdot \mathrm{L}^{-1}$ of coffee grounds and metal ion concentrations in the range 20-200 $\mu \mathrm{M}$. The results were then fitted to a Langmuir isotherm [7] as follows:

$$
\frac{1}{\mathrm{X}}=\frac{1}{b \mathrm{X}_{m} \mathrm{c}_{e}}+\frac{1}{\mathrm{X}_{m}}
$$

where $\mathrm{X}$ is the amount of metal ion adsorbed per $\mathrm{g}$ of adsorbent, $\mathrm{X}_{m}$ is the maximum amount of metal ion that 


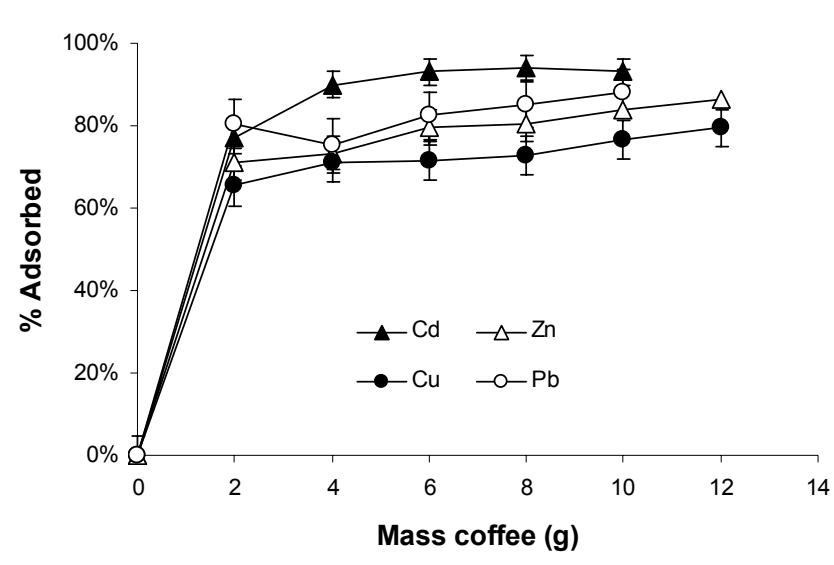

FIG. 1: Percentage of metal ion adsorbed from $200 \mathrm{~mL}$ solutions containing $10 \mathrm{mg} \cdot \mathrm{L}^{-1}$ of $\mathrm{Cu}(\mathrm{II})$ or $\mathrm{Pb}(\mathrm{II})$ or $1.0 \mathrm{mg} \cdot \mathrm{L}^{-1}$ of $\mathrm{Cd}(\mathrm{II})$ or $\mathrm{Zn}(\mathrm{II})$ at $\mathrm{pH} 5.0$ as a function of the mass of coffee adsorbent.

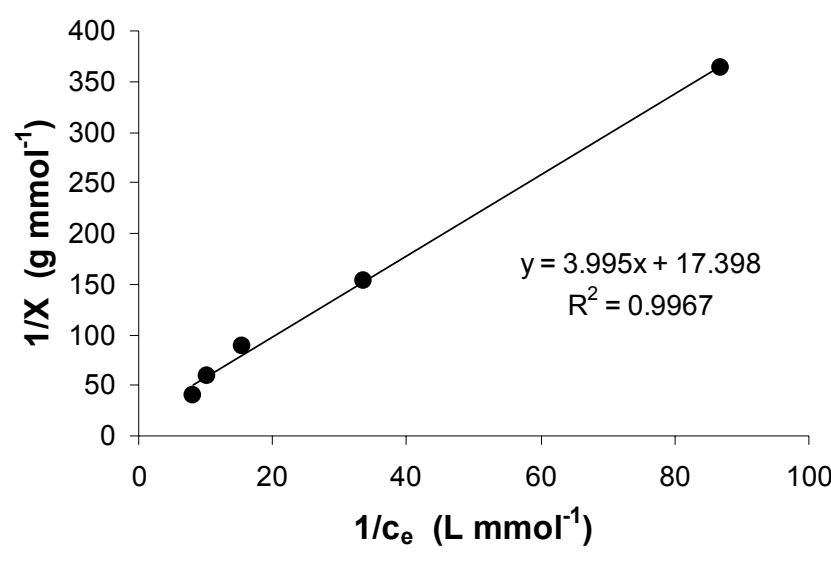

FIG. 2: Langmuir plot of Eq. (1) for adsorption of $\mathrm{Zn}(\mathrm{II})$ at $\mathrm{pH} 5.0$ on coffee adsorbent by $3 \mathrm{~g} \cdot \mathrm{L}^{-1}$ of coffee adsorbent. The least-square regression line and equation are shown.

can be adsorbed per $\mathrm{g}$ of adsorbent, $\mathrm{c}_{e}$ is the final equilibrium concentration of the metal ion in solution $(\mathrm{M})$ and $b$ is effectively the equilibrium constant for adsorption.

Figure 2 shows the Langmuir adsorption plot for $\mathrm{Zn}^{2+}$ adsorption. Linear least-squares regression was used to calculate $b$ and $\mathrm{X}_{m}$ from the best-fit line. Table I presents the resultant values for all of the metal ions studied.

Figure 3 shows the $\mathrm{pH}$ dependence of metal ion adsorp-

TABLE I: Langmuir adsorption parameters for the 4 metal ions for $3 \mathrm{~g} \cdot \mathrm{L}^{-1}$ coffee grounds at $\mathrm{pH}$ 5.0. The least-squares regression line and regression coefficient $r^{2}$ for the Langmuir plot (Fig. 2) are also shown.

\begin{tabular}{llll}
\hline \hline Metal Ion & $r^{2}$ & $\begin{array}{l}\mathrm{X}_{m} \\
\left(\mathrm{mmol} \cdot \mathrm{g}^{-1}\right)\end{array}$ & $\begin{array}{l}b \\
\left(\mathrm{~L} \cdot \mathrm{mmol}^{-1}\right)\end{array}$ \\
\hline $\mathrm{Pb}^{+2}$ & 0.9911 & 0.2388 & 1.229 \\
$\mathrm{Cd}^{2+}$ & 0.9951 & 0.1032 & 2.414 \\
$\mathrm{Zn}^{2+}$ & 0.9967 & 0.0575 & 4.356 \\
$\mathrm{Cu}^{2+}$ & 0.9670 & 0.0306 & 6.291 \\
\hline \hline
\end{tabular}

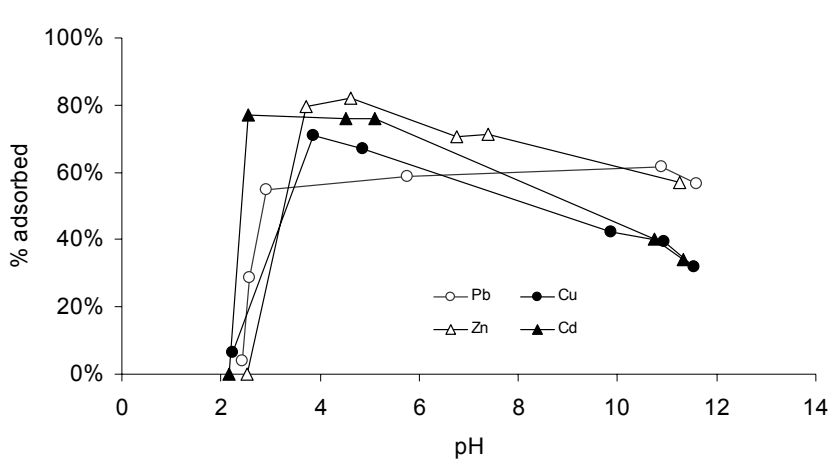

FIG. 3: Percentage of metal ion adsorbed by $10 \mathrm{~g} \cdot \mathrm{L}^{-1}$ of coffee adsorbent as a function of $\mathrm{pH}$ from solutions containing 10 $\mathrm{mg} \cdot \mathrm{L}^{-1}$ of $\mathrm{Cu}(\mathrm{II})$ or $\mathrm{Pb}(\mathrm{II})$ or $1.0 \mathrm{mg} \cdot \mathrm{L}^{-1}$ of $\mathrm{Zn}(\mathrm{II})$ or $\mathrm{Cd}(\mathrm{II})$.

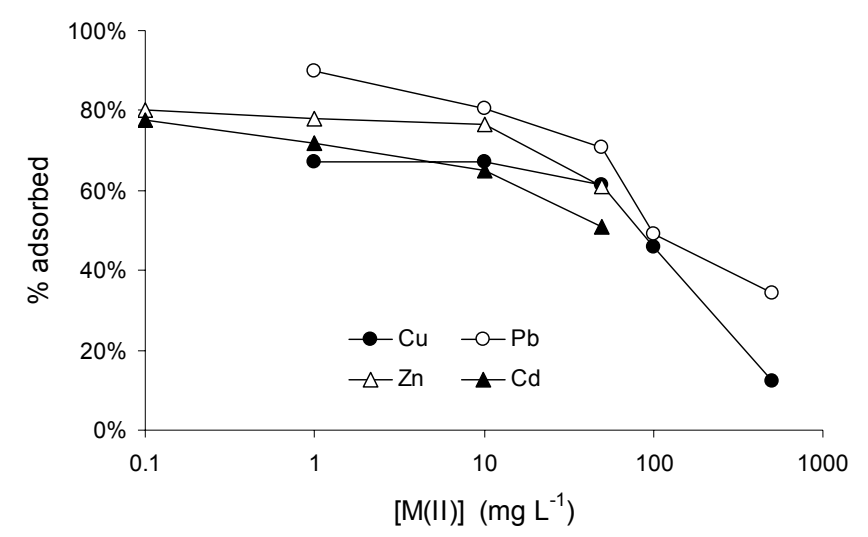

FIG. 4: Percentage of metal ion adsorbed as a function of metal ion concentration at $\mathrm{pH} 5.0$ by $10 \mathrm{~g} \cdot \mathrm{L}^{-1}$ of coffee adsorbent.

tion at fixed concentrations of metal ions and coffee adsorbent. The extent of adsorption was largely independent of $\mathrm{pH}$ over a wide $\mathrm{pH}$ range, but was significantly reduced at very low $(\mathrm{pH}<4)$ and to a lesser extent at high $\mathrm{pH}$ $(\mathrm{pH}>10)$. Good adsorption efficiency is observed at intermediate $\mathrm{pH}$ values likely to be encountered with many waste waters.

Figure 4 shows the percentage of metal ion adsorbed at $\mathrm{pH} 5.0$ from a suspension containing $10 \mathrm{~g} \cdot \mathrm{L}^{-1}$ of coffee as a function of the metal ion concentrations. In each case, the fraction adsorbed was fairly constant at metal ion concentrations below about $10 \mathrm{mg} \cdot \mathrm{L}^{-1}$ but at levels above $100 \mathrm{mg} \cdot \mathrm{L}^{-1}$ the adsorptive capacity of the coffee

TABLE II: Maximum adsorbed concentration of each metal $\mathrm{X}_{m}$ (from Table I) and the corresponding maximum solution concentration for $10 \mathrm{~g} \cdot \mathrm{L}^{-1}$ of coffee.

\begin{tabular}{lll}
\hline \hline Metal & $\begin{array}{l}\mathrm{X}_{m} \\
\left(\mathrm{mmol}_{\mathrm{g}} \mathrm{g}^{-1}\right)\end{array}$ & $\begin{array}{l}\mathrm{C}_{\max } \\
\left(\mathrm{mg} \cdot \mathrm{L}^{-1}\right)\end{array}$ \\
\hline & & \\
$\mathrm{Pb}$ & 0.2388 & 494.8 \\
$\mathrm{Cd}$ & 0.1032 & 115.6 \\
$\mathrm{Zn}$ & 0.0575 & 37.6 \\
$\mathrm{Cu}$ & 0.0306 & 19.4 \\
\hline \hline
\end{tabular}


TABLE III: Percentages of $\mathrm{Cd}(\mathrm{II})$ and $\mathrm{Zn}(\mathrm{II})$ adsorbed (1.0 $\left.\mathrm{mg} \cdot \mathrm{L}^{-1}, \mathrm{pH} 4.0\right)$ and then eluted in $0.1 \mathrm{M} \mathrm{HCl}$ during 4 repeated adsorption-elution cycles on a column containing $0.5 \mathrm{~g}$ of coffee adsorbent.

\begin{tabular}{|c|c|c|c|c|}
\hline & \multicolumn{2}{|c|}{$\mathrm{Cd}$} & \multicolumn{2}{|c|}{$\mathrm{Zn}$} \\
\hline & Adsorbed & Eluted & Adsorbed & Eluted \\
\hline 1 & 91.3 & 83.1 & 91.0 & 82.7 \\
\hline 2 & 98.9 & 99.5 & 99.7 & 100.0 \\
\hline 3 & 100.0 & 98.4 & 100.9 & 100.3 \\
\hline 4 & 100.0 & 98.4 & 100.9 & 99.7 \\
\hline
\end{tabular}

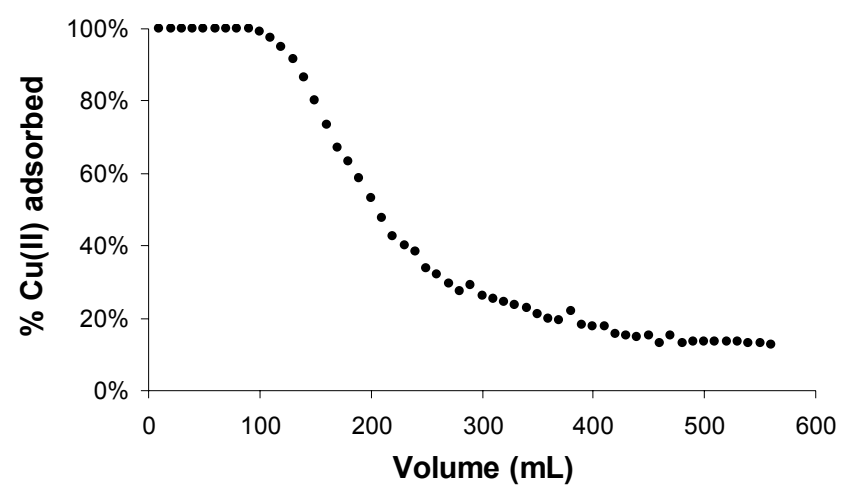

FIG. 5: Percentage of $\mathrm{Cu}(\mathrm{II})$ adsorbed by a column containing $0.5 \mathrm{~g}$ coffee adsorbent at $\mathrm{pH} 5.0$ and flow rate $3.3 \mathrm{~mL} \cdot \mathrm{min}^{-1}$ as a function of the volume of $10 \mathrm{mg} \cdot \mathrm{L}^{-1} \mathrm{Cu}$ (II) solution passed through the column.

was exceeded.

Table II shows the theoretical adsorption capacity for this concentration of coffee adsorbent calculated from the $\mathrm{X}_{m}$ values presented in Table I, from which it is clear that $\mathrm{Pb}(\mathrm{II})$ should exhibit the greatest limit for adsorption and $\mathrm{Cu}(\mathrm{II})$ the least. This is approximately in agreement with the results shown in Figure 4.

Column experiments indicated almost 100\% initial removal of metal ion from solution, with breakthrough occurring after the adsorption capacity of the adsorbent was exceeded, depending on $\mathrm{pH}$, flow rate, amount of column adsorbent and metal ion concentration. This is illustrated by Figure 5 for $\mathrm{Cu}(\mathrm{II})$. Using the $\mathrm{X}_{m}$ value reported in Table I for this cation, it was calculated that breakthrough should occur after $97 \mathrm{~mL}$ of $10 \mathrm{mg} \cdot \mathrm{L}^{-1} \mathrm{Cu}(\mathrm{II})$ solution had been passed through the column containing $0.5 \mathrm{~g}$ of coffee, which agrees very well with the breakthrough at $\sim 100 \mathrm{~mL}$ actually observed in this case.

Table III shows the result of repeated adsorptionelution experiments for $\mathrm{Cd}(\mathrm{II})$ and $\mathrm{Zn}(\mathrm{II})$. In each case, $100 \mu \mathrm{g}$ of metal ion comprising $100 \mathrm{~mL}$ of $1.0 \mathrm{mg} \mathrm{L}^{-1}$ solution was passed through a column containing $0.5 \mathrm{~g}$ of coffee. After rinsing with $50 \mathrm{~mL}$ of Milli-Q water, the column was eluted with $100 \mathrm{~mL}$ of $0.1 \mathrm{M} \mathrm{HCl}$ which was retained for analysis. The results show that after the first adsorption-elution cycle, both metal ions are quantitatively adsorbed by, and then eluted from, the column. However, there is some initial loss on the first cycle.

\section{CONCLUSION}

Our preliminary results indicate that exhausted coffee grounds offer considerable promise as a low-cost natural medium for waste water treatment. The adsorption is efficient over a fairly wide $\mathrm{pH}$ range and adsorbed metals are reversibly leached from the exhausted coffee by dilute acid without significant loss of the adsorptive capacity for subsequent re-use.

\section{Acknowledgments}

The authors are grateful to the University of Otago for financial support.
[1] S. E. Bailey, T. J. Olin, and R. Bricka, A review of potentially low-cost sorbents for heavy metals, Water Res. 33, 2469-2479 (1999).

[2] K. S. Low, C. K. Lee, S. Y. Wong, Metal sorption enhancement of rice hull through chemical modification, Env. Tech. 21, 1239-1244 (2000).

[3] P. Hawken, in Specialty Coffee Association of America Conference, San Francisco, 2000.

[4] Y. Orhan and H. Buyukgungor, The removal of heavy metals by using agricultural wastes, Water Sci. Technol. 28, 247-255 (1993).
[5] W. T. Tan, Copper (II) adsorption by waste tea leaves and coffee powder, Pertanika 8, 223-230 (1985).

[6] H. Djati Utomo and K. A. Hunter, Adsorption of divalent copper, zinc, cadmium and lead ions from aqueous solution by waste tea and coffee adsorbents, Env. Tech. 27, 25-32 (2006).

[7] G. Macchi, D. Marani, and G. Tiravanthi, Uptake of mercury by exhausted coffee grounds, Env. Tech. Lett. 7, 431444 (1986). 